\title{
Dominant Vertical Orientation Processing without Clustered Maps: Early Visual Brain Dynamics Imaged with Voltage-Sensitive Dye in the Pigeon Visual Wulst
}

\author{
Benedict Shien Wei Ng, ${ }^{1,3}$ Agnieszka Grabska-Barwińska, ${ }^{1,4}$ Onur Güntürkün, ${ }^{2,3}$ and Dirk Jancke ${ }^{1,3,4}$ \\ ${ }^{1}$ Cognitive Neurobiology, ${ }^{2}$ Department of Biopsychology, ${ }^{3}$ International Graduate School of Neuroscience, and ${ }^{4}$ Bernstein Group for Computational \\ Neuroscience, Ruhr University Bochum, D-44780 Bochum, Germany
}

\begin{abstract}
The pigeon is a widely established behavioral model of visual cognition, but the processes along its most basic visual pathways remain mostly unexplored. Here, we report the neuronal population dynamics of the visual Wulst, an assumed homolog of the mammalian striate cortex, captured for the first time with voltage-sensitive dye imaging. Responses to drifting gratings were characterized by focal emergence of activity that spread extensively across the entire Wulst, followed by rapid adaptation that was most effective in the surround. Using additional electrophysiological recordings, we found cells that prefer a variety of orientations. However, analysis of the imaged spatiotemporal activation patterns revealed no clustered orientation map-like arrangements as typically found in the primary visual cortices of many mammalian species. Instead, the vertical orientation was overrepresented, both in terms of the imaged population signal, as well as the number of neurons preferring the vertical orientation. Such enhanced selectivity for the vertical orientation may result from horizontal motion vectors that trigger adaptation to the extensive flow field input during natural behavior. Our findings suggest that, although the avian visual Wulst is homologous to the primary visual cortex in terms of its gross anatomical connectivity and topology, its detailed operation and internal organization is still shaped according to specific input characteristics.
\end{abstract}

\section{Introduction}

The avian and mammalian pallia are homologous (Reiner et al., 2004; Jarvis et al., 2005). Within this homologous entity, the avian visual Wulst bears a close resemblance to the mammalian primary visual cortex (V1). This similarity could be result of a one-to-one homology of the visual Wulst and visual cortex (Karten et al., 1973; Medina and Reiner, 2000). This inference is backed mainly by similarities in its chemoarchitecture, its afferent anatomical connectivity from the thalamic nucleus geniculatus pars dorsolateralis (GLd) (Karten et al., 1973) (for revised nomenclature, see Reiner et al., 2004) and its efferent output to thalamic and midbrain structures, relevant genetic markers, as well as its local topology (Karten et al., 1973; Reiner et al., 2004). However, since some structural and physiological traits between Wulst and cortex evolved independently in birds and mammals, these two structures could also represent a case of a close convergent evolution (Medina and Reiner, 2000).

Our current knowledge about its functional properties is mostly derived from key studies in the owl (Pettigrew and Konishi,

\footnotetext{
Received Aug. 19, 2009; revised Feb. 5, 2010; accepted March 12, 2010.

This work was financially supported by Bundesministerium für Bildung und Forschung (D.J., A.G.-B.), International Graduate School of Neuroscience (B.S.W.N., D.J.), and Deutsche Forschungsgemeinschaft (0.G.) [Sonderforschungsbereich Neurovision 509 (K.-P. Hoffmann, C. Distler)]. We thank Dr. Janina Kirsch for guidance with the initial surgical procedures. We thank Dr. Hubert Dinse for valuable comments on this manuscript.

Correspondence should be addressed to Dirk Jancke, Bernstein Group for Computational Neuroscience, Institut für Neuroinformatik, Ruhr-Universität Bochum, Universitätstrasse 150, D-44780 Bochum, Germany. E-mail: jancke@neurobiologie.rub.de.

DOI:10.1523/JNEUROSCI.4078-09.2010

Copyright $\odot 2010$ the authors $\quad 0270-6474 / 10 / 306713-13 \$ 15.00 / 0$
}

1976; Pettigrew, 1979; Nieder and Wagner, 2001). The owl visual Wulst is retinotopically organized and contains both simple and complex cells tuned to basic visual parameters such as orientation, direction, and end-stopping (Pettigrew, 1979; Nieder and Wagner, 1999). Cells are clustered into functional orientation domains, similar to those found in many mammalian striate cortices (Liu and Pettigrew, 2003). Particularly, the owl visual Wulst is extensively involved in the interpretation of binocular interaction (Pettigrew and Konishi, 1976; Pettigrew, 1979; Nieder and Wagner, 2001) and additionally performs more complicated functions, such as the representation of illusory contours (Nieder and Wagner, 1999). Despite excellent optics and a well developed visual Wulst, the barn owl's behavioral acuity belongs to the lower end of examined birds (Harmening et al., 2009).

Therefore, surprisingly, much less is certain about the visual Wulst of the pigeon, a highly visual bird routinely and intensively used in well elaborated behavioral tasks aimed at studying the higher processes of avian visual cognition. Pigeons are known to be able to place objects into visual categories (Ghosh et al., 2004; Lazareva et al., 2004, 2006; Yamazaki et al., 2007), visually conceptualize abstract (e.g., same-different) relationships (Cook et al., 1997; Cook and Smith, 2006; Brooks and Wasserman, 2008), and visually complete incompletely represented objects (Aust and Huber, 2006; Nagasaka and Wasserman, 2008). The physiological function of the pigeon visual Wulst is often extrapolated from the knowledge of the owl visual Wulst. However, this practice is not straightforward because these two structures process information that is qualitatively different, the pigeon receiving mainly monocular input from the lateral visual field, compared 
with the owl's dominant binocular vision (Remy and Güntürkün, 1991; Güntürkün and Hahmann, 1999).

As a first step toward bridging this knowledge gap, we here applied high-resolution voltage-sensitive dye (VSD) optical imaging in combination with extracellular recordings to examine the functional organization in the visual Wulst of the anesthetized pigeon in vivo. Particularly, as the clustered arrangement of cortical neurons into orientation modules has been regarded as a prominent organizing feature of early processing steps in the visual pathway, we here focus on activity patterns evoked by oriented stimuli.

\section{Materials and Methods}

Animal preparation

A total of nine unsexed, adult homing pigeons (Columba livia) were used in this study. All surgical and experimental procedures were approved by the German Animal Care and Use Committee (AZ 9.93.2.10.32.07.093) in accordance with the National Institutes of Health guidelines.

Initial anesthesia was applied using ketamine $\left(70 \mathrm{mg} \cdot \mathrm{kg}^{-1}, \mathrm{i} . \mathrm{m}\right.$.) and xylazine $(6.0$ $\mathrm{mg} \cdot \mathrm{kg}^{-1}, \mathrm{i} . \mathrm{m}$.), supplemented with atropine $\left(0.025 \mathrm{mg} \cdot \mathrm{kg}^{-1}\right.$, i.m.). Extensive care was taken to cater to the relatively high metabolic rates of birds. Pigeons were not fasted overnight before the introduction of anesthesia since we did not experience any emetic responses from the pigeons known to be associated with some bolus anesthetics (e.g., urethane). An intravenous catheter was placed into the wing vein to permit intravenous infusion of saline $\left(4.5 \mathrm{ml} \cdot \mathrm{kg}^{-1} \cdot \mathrm{h}^{-1}\right)$ to compensate for fluid loss. After the placement of a plastic cannula into the trachea, each subject was head fixed in the stereotactic position. Each subject was then connected to an artificial respirator (Ugo Basile) and ventilated with a 1:1 mixture of $\mathrm{O}_{2}$ and $\mathrm{N}_{2} \mathrm{O}$. After respiration parameters were optimized, isoflurane (Abbott Laboratories) was added to the ventilation air stream (gradually increasing to $1.2-1.3 \%$ of inspired volume), to maintain a stable plane of anesthesia for the rest of the experiment. We regularly checked for the absence of withdrawal reflexes by gently pinching the feet with rounded pincers. Rectal temperature was maintained at $42^{\circ} \mathrm{C}$ with a water heating blanket. Electrocardiogram, heart rate, intratracheal pressure, and end-tidal $\mathrm{CO}_{2}$ were constantly monitored until the end of the experiment.

A craniotomy was made over the right visual Wulst guided by stereotactic coordinates (Karten and Hodos, 1967). As the original stereotactic head position was neither the pigeon's natural head position (Erichsen et al., 1989) nor was it conducive for simultaneous optical access and visual stimulation, we rotated the head (supplemental Movie 1, available at www.jneurosci.org as supplemental material) such that the ear-beak axis was at
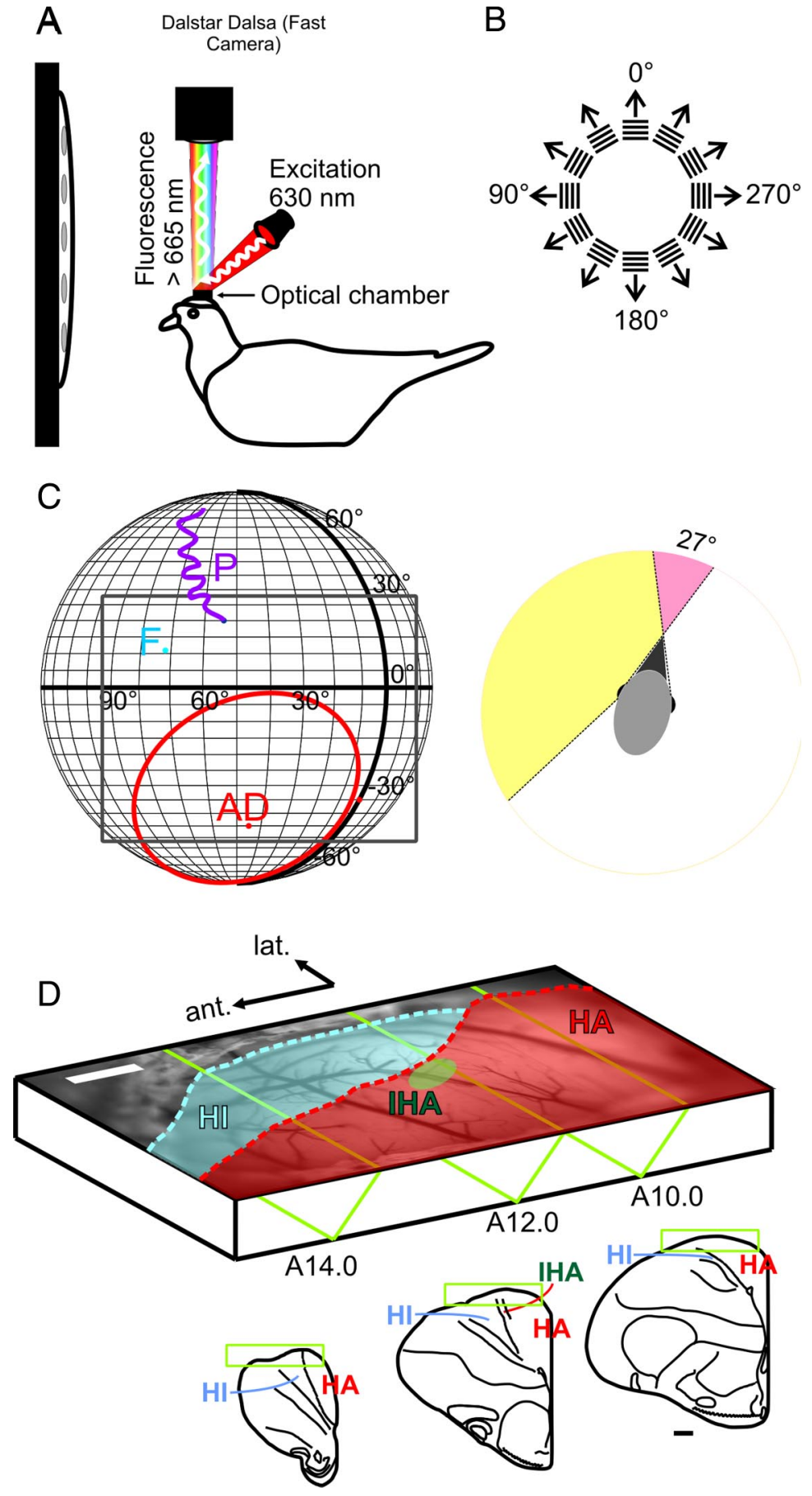

Figure 1. VSD imaging in the pigeon visual Wulst in vivo. $A$, Schematic of the experimental setup. Anesthetized and paralyzed pigeons were head-fixed via a sealed custom optical chamber. Epifluorescent signals arising from the VSD-stained visual Wulst were captured by a fast $C C D$ camera operating at $200 \mathrm{~Hz}$. B, Activity was evoked using sinusoidal and square wave gratings at various spatiotemporal frequencies in $30^{\circ}$ steps. $C$, Left, Visual features of the retina mapped onto real-world coordinates. The pigeon retina contains two local photoreceptor densities. The receptive field of area dorsalis (AD) or "red" field is frontal and ventral (red contour), and photoreceptors project mainly into the tectofugal system. The foveal pit (F) resides in the "yellow" field. This region receives visual input mostly from the lateral visual field and projects into the thalamofugal pathway. The pecten $(P)$ is a large vascular structure of unknown function but served in this study as a retinal landmark for controlling eye movements and placement of visual stimulus. Gratings were presented on a flat screen monitor covering $\sim 120 \times 80^{\circ}$ of the visual field (gray rectangle). Right, The pigeon's visual field is highly lateralized with a dominantly monocular visual field spanning $169^{\circ}$. Compared with the owl, its binocular overlap is minimal $\left(27^{\circ}\right)$. D, Vascular map of the exposed Wulst region used for targeted electrode penetrations. The dura has been carefully resected. The schematic also presents the imaging position in which the brain was rotated $45^{\circ}$ upward from the standard stereotactic position. Outsets show stereotactic slices (Karten and Hodos, 1967). Contours approximate regions where HA (red) and HI (blue) extrude the brain surface. The surface position of the input pseudolamina, IHA (A12.0; green ellipse), was inferred from the study by Karten et al. (1973). Scale bars (white and black), $1 \mathrm{~mm}$. 


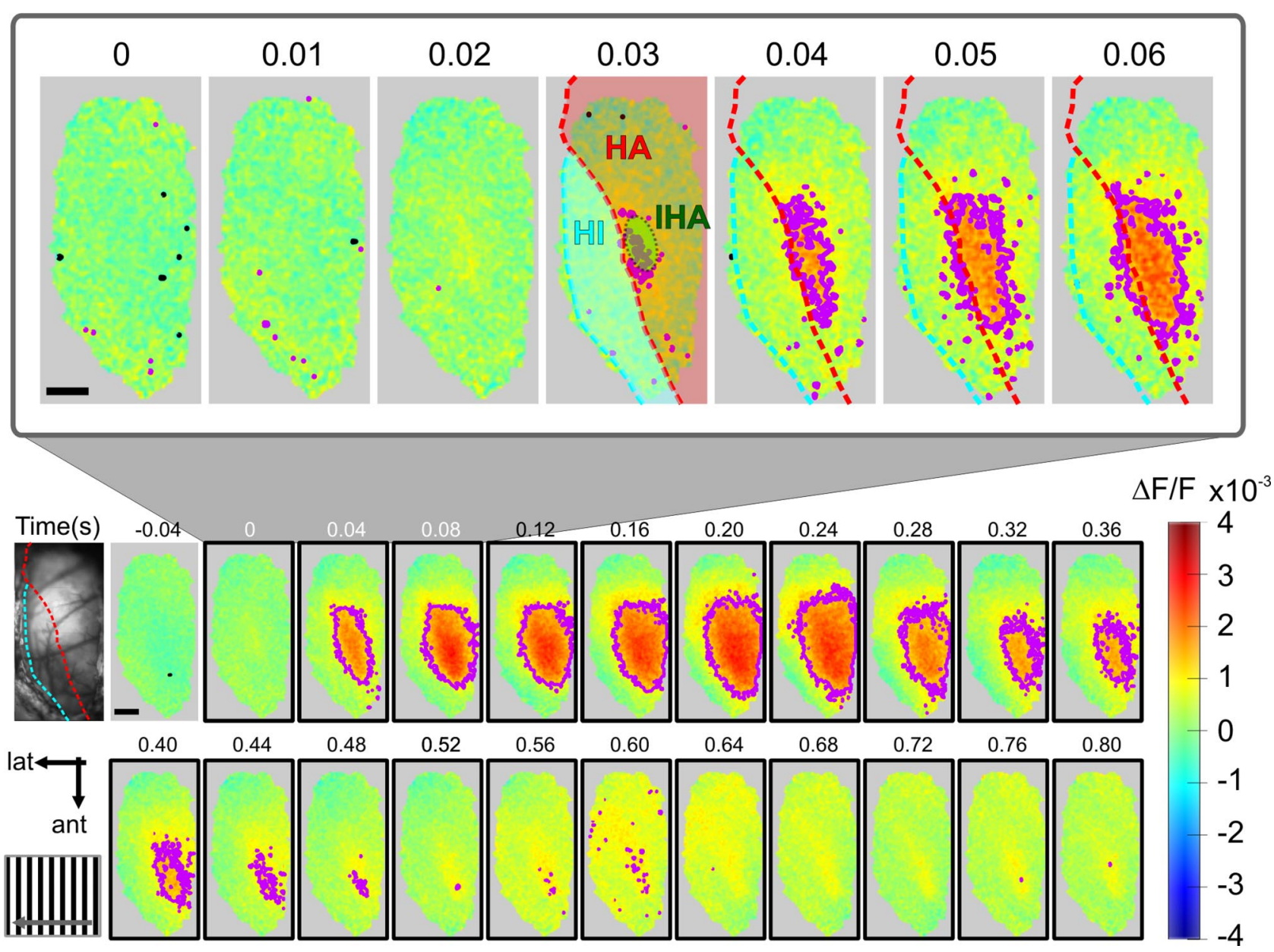

Figure 2. Spatiotemporal characteristics of the Wulst response. Imaged response to a vertical grating drifting in the direction from frontal to lateral. Each imaging frame corresponds to the vascular map image (first frame) and is pseudocolored in which warm colors represent increase in activity $(\Delta F / F)$ (see Materials and Methods) and colder colors represent fluorescence decrease. Collected VSD signals were typically of high amplitude $(\sim 3 \%)$. Pixels corresponding to bone or unresected dura were excluded. The time course is shown in $40 \mathrm{~ms}$ binned frames, and stimulus duration was $800 \mathrm{~ms}$. The purple contours indicate regions coding significantly at $p<0.01\left(\mathrm{~F} / F_{0}\right.$ amplitudes significantly different from blank, as tested across $n_{k}=15$ trials) (see Materials and Methods). The outset demonstrates initial response to the stimulus onset (zero) in $10 \mathrm{~ms}$ resolution. A significant response (purple contour) starts locally, $\sim 30 \mathrm{~ms}$ after stimulus onset, and quickly spreads across most of the recording frame. The red stippled line divides between HA and HI, and the green ellipse approximates the surface extrusion of IHA (compare Fig. 1 legend). Sporadically, the analysis method assigned individual pixels to be significantly below baseline levels $(p<0.01$, black contour). Scale bars, $1 \mathrm{~mm}$.

$90^{\circ}$, parallel to the ground. A custom aluminum chamber was fixed to the bone surrounding the craniotomy with methyl acrylate resin (Technovit 4004; Heraeus Kulzer). The animal was then transferred out of the stereotactic device and was head fixed by means of the chamber for the remaining experiment. The chamber was then filled with Stereofundin (Braun) and sealed with a glass plate. After surgery, the pigeon was paralyzed with Alloferin $\left(0.08 \mathrm{mg} \cdot \mathrm{kg}^{-1} \cdot \mathrm{h}^{-1}\right.$; Valeant Pharmaceuticals $)$ to prevent any possibility of slow eye movements. The left eye was kept open by means of sterile sticky tape and pupils were dilated with drops of $0.5 \%$ atropine sulfate. Both eyes were periodically flushed with saline to prevent them from drying out.

In the absence of a clearly identifiable fovea with a portable ophthalmoscope, we looked to another prominent retinal structure, the pecten for the control of eye position. We regularly measured the position of its tip (near the area centralis), along with two additional positions along its folds. These were then marked by backprojecting their measured positions onto a glass panel placed $15 \mathrm{~cm}$ away from the left eye. The ear-beak axis, eye-beak axis, and beak axis (where the beak was pointing) were also mapped onto the glass panel, all to control for stimulus position across animals.

\section{Stimulus presentation}

Stimuli were presented on a $24^{\prime \prime}$ Sony Trinitron monitor (GDM-FW, operating at $100 \mathrm{~Hz}$ ) covering $\sim 120 \times 80^{\circ}$ of the visual field (see Fig. $1 C$ ).
We used a set of isoluminant sinusoidal gratings of various spatiotemporal frequencies $\left(0.03-0.5\right.$ cycles $/{ }^{\circ} ; 1-5$ cycles/s) generated by the VSG2/5 system (Cambridge Research Systems) running on custom scripts written for Matlab 6.5 (The MathWorks). In addition, each trial consisted of two "blank" conditions (uniform gray screen) that serves as reference. All stimuli had the same mean luminance of $55.9 \mathrm{~cd} / \mathrm{m}^{2}$. In most experiments, gratings drifting in 12 different directions ( $30^{\circ}$ steps) were used. Two additional experiments with electrophysiology were performed with decreased number of stimuli (eight directions, $45^{\circ}$ steps) to more rapidly characterize the tuning properties of cells and improve the sample size collected per subject. For extracellular recordings, the optimal spatiotemporal frequencies were chosen on maximal activation of the unit. For optical imaging, the spatiotemporal frequency used was based on preimaging electrophysiology. Within each trial, the isoluminant gratings were individually presented in random order. Prestimulus time was $220 \mathrm{~ms}$, and interstimulus interval during imaging was $30 \mathrm{~s}$.

In some experiments, local grating patches $\left(20 \times 20^{\circ}\right)$ were presented to map retinotopy. Example responses to two such patches are shown in supplemental Figure 3 (available at www.jneurosci.org as supplemental material).

\section{Electrophysiology}

Electrode recordings complement imaging experiments by further enhancing temporal resolution and also serve as a control of the voltage- 
related responses reported by the VSD. As such, most of our recorded units were collected at a depth between 400 and $800 \mu \mathrm{m}$. Before electrophysiology, a vascular map of the brain was captured by illuminating the brain with green light $(546 \mathrm{~nm})$ from two optic fiber light guides. This map was then used to guide electrode penetrations and have proved particularly useful to perform targeted penetrations after imaging. Recordings before imaging were done through an intact dura. Multipleunit signals recorded by a glass-insulated tungsten electrode (1-2 M $\Omega$ ) were spike sorted by multiple spike detector (MSD) (Alpha Omega Engineering) to identify single units.

\section{VSD imaging}

Optical imaging of VSD was so far mostly applied to explore the in vivo functional architecture of the mammalian neocortex at high spatial (up to $50 \mu \mathrm{m}$ ) and temporal (millisecond) resolution (Grinvald et al., 1994; Seidemann et al., 2002; Jancke et al., 2004; Sharon et al., 2007; Palagina et al., 2009) (but see Prechtl et al., 1997; Senseman and Robbins, 1999, for VSD imaging in the turtle visual brain in vivo). The VSD binds to the external surfaces of all excitable membranes. On excitation, the amount of emitted fluorescence changes linearly with fluctuations in membrane potential, shown using intracellular recordings in cat visual cortex (Sterkin et al., 1998) and rat somatosensory cortex (Petersen et al., 2003). In vivo, however, each imaging pixel reports the summed potentials across large neuronal populations, primarily reflecting postsynaptic activity present in the focal plane.

To access the Wulst, its overlying dura mater was excised, taking exceptional care not to perturb the underlying brain tissue. The brain was then stained with the blue voltage-sensitive dye RH-1838 (Optical Imaging) for $3 \mathrm{~h}$. After staining, the chamber was carefully and gently flushed with Stereofundin (Braun) to remove unbound dye. In our preparation, we found the VSD to perfuse approximately the upper $800 \mu \mathrm{m}$ of the Wulst.

Optical imaging was done using an Imager 3001 interface (Optical Imaging). Image acquisition was accomplished by a CCD camera (Dalstar; Dalsa) coupled to a tandem lens system $(85 \mathrm{~mm} / 1.2$ to camera; $50 \mathrm{~mm} / 1.2$ to subject) (Ratzlaff and Grinvald, 1991). The camera was focused at a depth of $\sim 600 \mu \mathrm{m}$ below the Wulst surface. Bound VSD was excited by illumination of the Wulst surface with stable source (Kepco) of red light $(630 \pm 10 \mathrm{~nm})$. The emitted light was filtered with cutoff at $665 \mathrm{~nm}$. We acquired images of the brain with a frame rate of $200 \mathrm{~Hz}$ across a $9.0 \times 4.5$ $\mathrm{mm}$ field. These images were binned temporally on chip to produce an output frame rate of $100 \mathrm{~Hz}$.

\section{Optical imaging of intrinsic signals}

In three subjects, intrinsic signals were recorded before VSD imaging. Procedurally, this was mostly similar to VSD imaging except that the brain was illuminated with orange light $(605 \pm 10 \mathrm{~nm})$ via light guides. No postfilter was applied. Data were acquired at a frame rate of $200 \mathrm{~Hz}$ and binned temporally on chip such that the resulting frame rate was $0.5 \mathrm{~Hz}$. Gratings were presented for $8000 \mathrm{~ms}$, commencing $800 \mathrm{~ms}$ (two frames) after the start of camera recording.

\section{Data analysis}

VSD imaging data. All data were analyzed using custom scripts running on Matlab 7.

Preprocessing began by spatially filtering each recorded frame with a low-pass Gaussian $(\sigma=2$ pixels $=0.035 \mathrm{~mm}$; size $=13 \times 13$ pixels $=$ $0.23 \times 0.23 \mathrm{~mm}$ ) to the end of reducing camera shot noise. Each frame

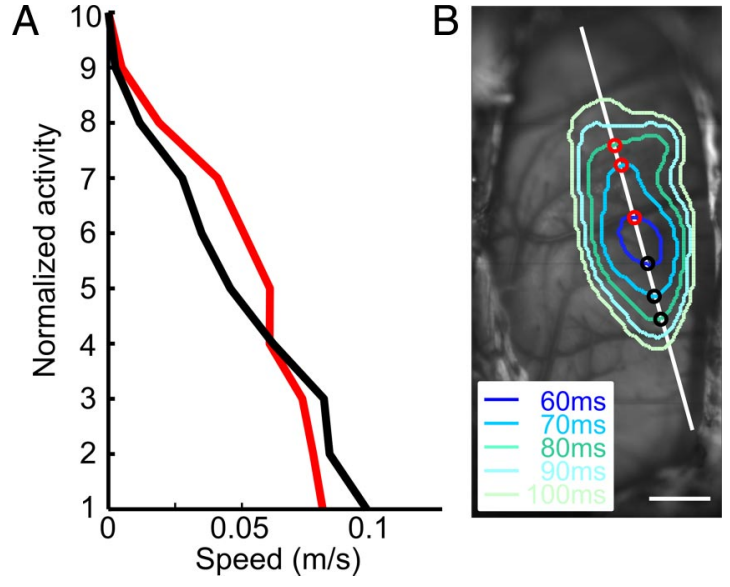

Figure 3. Speed of spread. $A$, Speed of spread (in meters/second) along anterior (black) and posterior (red) directions as a function of normalized activity levels: 10 , peak activation; 1 , significance threshold $(p<0.01)$. $\boldsymbol{B}$, Vascular map overlaid with successive contours at activity level 3 (see $\boldsymbol{A})$. Spread was defined as the shortest distance between two successive contours along an axis of spread. Anterior spread was plotted with black dots, and posterior spread, with red dots. Speed was defined as the gradient of a linear regression line passing through the first three spread points.
A VSD Imaging

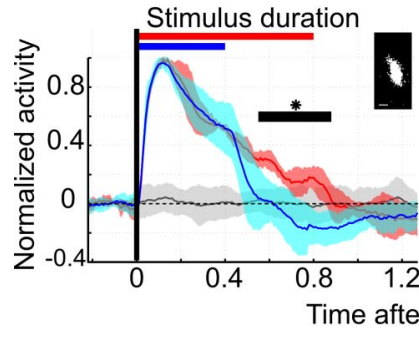

B Electrophysiology

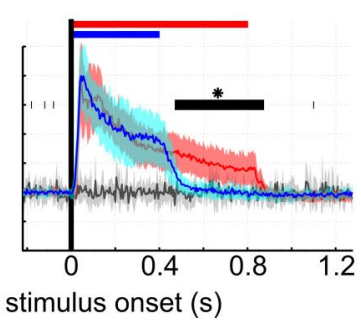

C Offset-Latency difference [long-short stimulation] (sec)
Figure 4. Temporal dynamics distinguish two regions of the visual Wulst. $\boldsymbol{A}$, Input region response to different stimulus duration. The inset shows an example of the pixels belonging to the central input region in one subject. Relative VSD reflectance $(\Delta F / F)$ averaged over input area and stimulus conditions is shown as a mean across experiments (after normalization to the maximum). Response to the gratings moving for $400 \mathrm{~ms}$ is shown in blue, and the $800 \mathrm{~ms}$ stimulation is drawn in red. For comparison, one of the two responses to a gray screen is shown (in black). The shaded areas depict SD of normalized $\Delta F / F$ values evaluated across animals ( $N=9$ for $400 \mathrm{~ms}$ stimulation; $N=5$ for $800 \mathrm{~ms}$; and $N=9+5$ for the blanks). The black bars show the time period in which the two stimuli evoked a significantly different response (unpaired $t$ test, $p<0.05$ ). $\boldsymbol{B}$, Time course of activity recorded with electrophysiology. Similar analysis was applied to electrode recordings, in which $5 \mathrm{~ms}$ binned frequency responses were averaged across all available cells in all subjects, and normalized to the maximum (in contrast to $A$, no blank subtraction was performed and the mean of prestimulus activity preceding the stimulus onset was subtracted, and not divided). The shaded region depicts $S D$ across experiments $(N=12$ for $400 \mathrm{~ms}, N=11$ for $800 \mathrm{~ms}$ stimulation). For each animal, data from 1 to 18 cells was available (in overall, 53 cells for $400 \mathrm{~ms}$, and 77 cells for $800 \mathrm{~ms}$ stimulation). Initial activity peaks at $\sim 50 \mathrm{~ms}$, followed immediately by biphasic decay, first a fast decrease to a stable activity level and dropping slightly below the baseline after the stimulus offset. C, Twodimensional map from one pigeon presenting the difference in offset latency recorded in 800 and 400 ms stimulation paradigms. Offset was defined as a time at which significance of a given pixel response (averaged across stimulus orientations) dropped below 1, $p<0.99$ (for single-condition contours, see Fig. 2).

was subsequently binned spatially four times, resulting in a final spatial resolution of $0.071 \mathrm{~mm}$. After, each pixel luminance was divided by its average activity across $200 \mathrm{~ms}$ (frames 1-20) before stimulus onset (frame 22 ), denoted as $F / F_{0}$. Finally, activity in a given condition $\left(F_{C} / F_{0 C}\right)$ was compared with the activity recorded in response to an isoluminant gray screen (blank) as follows:

$$
\Delta F / F=F_{\mathrm{C}} / F_{0 \mathrm{C}}-F_{\mathrm{B}} / F_{0 \mathrm{~B}},
$$

where $F_{\mathrm{B}} / F_{\mathrm{OB}}$ stands for the mean response to the two blank conditions. Pixels that did not correspond to brain tissue (i.e., surrounding bone or unresected dura mater) were excluded from additional analyses. 


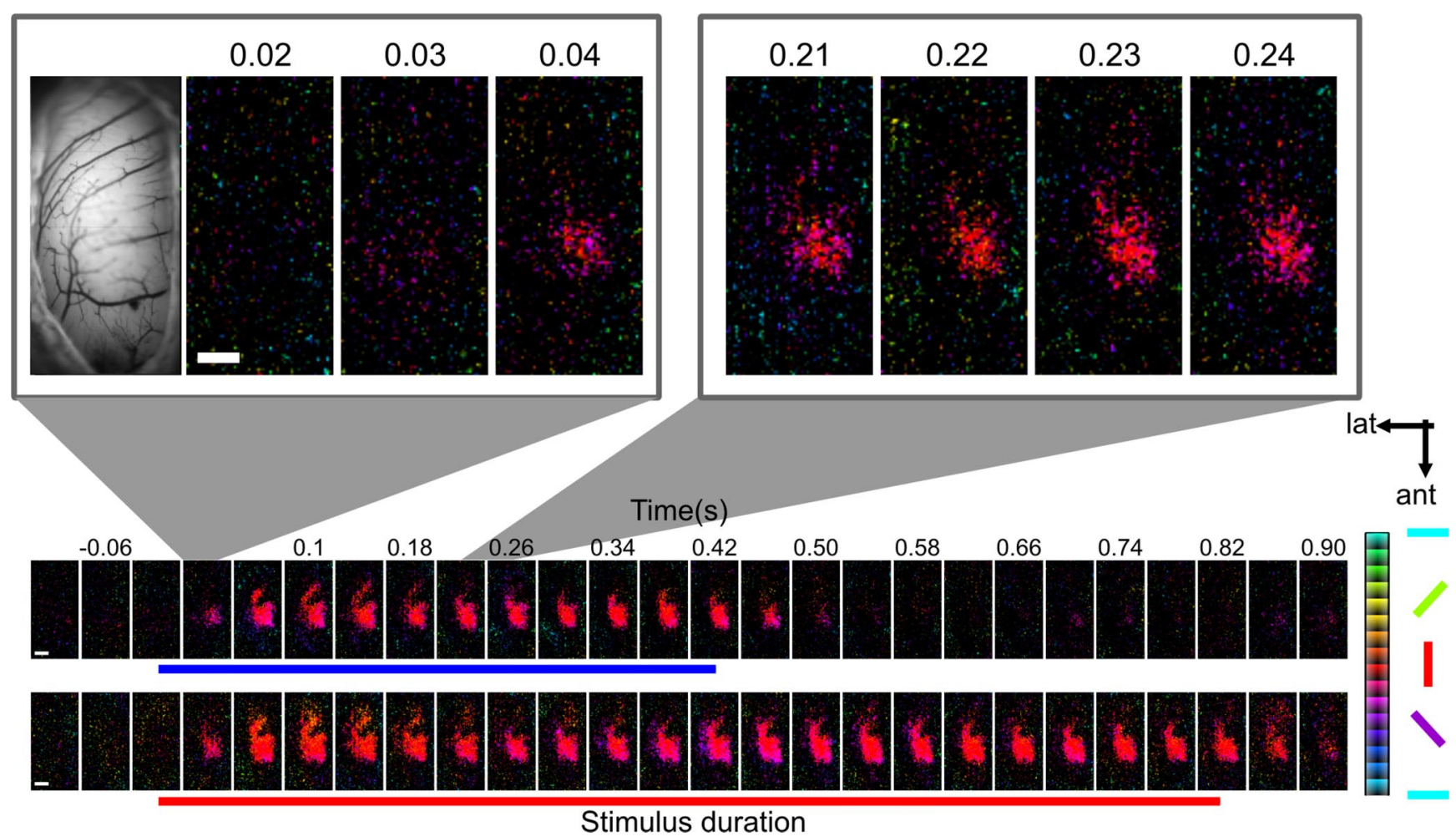

Figure 5. Orientation anisotropy in the visual Wulst. The spatiotemporal dynamics of orientation preference in a representative subject. Polar maps recorded in response to a short (400 ms stimulus) and long (800 ms stimulus) stimulus are shown in $40 \mathrm{~ms}$ time steps. Pixels were color-coded according to their orientation preference. Pixel brightness represents the trialwise reproducibility of orientation preference ("short": $n_{k}=19$ trials; "long": $n_{k}=16$ trials): brightest pixels were selective with $p<0.05$, the orientation coding of the black pixels was insignificant with $p \geq 0.5$ (see Materials and Methods for the derivation of $p$ values). Maps were bandpass filtered (using low-pass Gaussian filters with $s=0.035 \mathrm{~mm}$ and $s=7 \mathrm{~mm}$, the second one used to remove the low-frequency fluctuations). Scale bar, $1 \mathrm{~mm}$.

The significance of the measured signal $(\Delta F / F)$ was evaluated across repeated measurements (the number of trials ranging between $n_{k}=10$ and $\left.n_{k}=30\right)$ as follows:

$$
z=\Delta F / F^{*}\left(\mathrm{SE}\left(F_{\mathrm{C}} / F_{0 \mathrm{C}}\right)^{2}+\mathrm{SE}\left(F_{\mathrm{B}} / F_{0 \mathrm{~B}}\right)\right)^{-1 / 2},
$$

where $\Delta F / F$ stands for the mean, and SE stands for the SE across trials.

When detecting the localized region of initial activity ("input region"), the mean frame activity was removed in each trial before calculating the $z$-score to increase the test sensitivity (decreasing the influence of the luminance drift).

For depiction (see Figs. 2-4), we used $z$-score value of $2.56(p<0.01)$, but the results did not vary within a reasonable range of thresholds (smaller thresholds yielding more single-pixel noise in the patterns and higher thresholds decreasing the size of significant regions).

Spread of activity was defined as the shortest distance between successive contours along a given axis (see Fig. $3 B$ ). The spread velocity of the intersection points gathered from three initial consecutive frames (i.e., first $20 \mathrm{~ms}$ ) defined the initial spread velocity, approximated with linear regression. This time period was chosen since the spread of activity was often rapid, reaching the extremities of the Wulst (therefore slowing down) after this time.

To compute "VH" differential maps, we first obtained orientation responses by averaging the responses to gratings that were drifting in opposite directions. The subtractive difference maps between orthogonal orientations were then computed for each frame in the time course; only the first frame in which significant activity was found is presented in Figure 6.

Electrophysiology. Peristimulus time histograms (PSTHs) were calculated by averaging the spike counts across $20-30$ repetitions. To the end of increasing signal-to-noise ratio, we used temporal binning of $5 \mathrm{~ms}$ (in Figs. $4 B, 7 D$ ), and no filtering was performed. To facilitate comparison to the VSD imaging time courses (see Fig. $4 A$ ), we additionally subtracted the mean activity from $200 \mathrm{~ms}$ of prestimulus period and normalized the time course to the maximum (see Fig. $4 B$ ). All recorded units were sorted into two groups depending on the stimulus duration. PSTHs were then averaged across all cells in the group, and the statistical tests were performed on these averages across animals.

Orientation preference. Orientation response was first obtained by averaging neural responses to gratings drifting in opposite directions to obtain equally spaced orientations covering the range between 0 and $180^{\circ}$.

Preferred orientation (PO) was evaluated by vector averaging as follows:

$$
\mathrm{PO}=1 / 2 \arg \left(\sum_{\varphi}\left(f(\varphi) * e^{2 i \varphi}\right)\right)
$$

where $f(\varphi)$ is the response to the orientation $\varphi$ displayed on the screen.

Such evaluation was performed for every trial separately, so that an average preferred orientation $\langle\mathrm{PO}\rangle$ and its selectivity could be estimated by vector averaging preferred orientations across trials as follows:

$$
\begin{gathered}
\langle\mathrm{PO}\rangle=1 / 2 \arg \left(\sum_{k} e^{2 i \mathrm{PO}(k)}\right) \\
r=1 / n_{k}\left|\sum_{k} e^{2 i \mathrm{PO}(k)}\right|
\end{gathered}
$$

where $k$ stands for a single trial (one of $n_{k}$ trials), |.| is the vector length, and $r$, called reproducibility (Grabska-Barwinska et al., 2009), measures how much single-trial responses are spread around the average preferred orientation.

Reproducibility can take values from 0 to 1 , with 1 achieved only when the same preferred orientation is evaluated in every single trial. In an extreme example, when only one trial is available, $r=1$. The significance of orientation coding measured with different number of trials therefore 
requires additional evaluation. For every experiment, we tested how often the measured $r$ value would occur as a result of a random process. The surrogate data sample was created by vector averaging $n_{k}$ random orientations, and its distribution estimated by repeating the procedure 10,000 times. Finally, we estimated $p$ values by calculating cumulative distribution of the surrogate values that were larger than the recorded $r$ value (the brightness scale in Fig. 5 was based on this procedure).

Vector averaging was also used to obtain an average orientation over a region of interest (derived from VSD imaging), by substituting $k$ in Equation 4 with a pixel index, or over single neurons, by having $\mathrm{PO}(k)$ represent an average preferred orientation of a single cell in a given pigeon.

Finally, we used vector averaging of preferred orientations to evaluate the average preferred orientation across experiments (both for VSD imaging and electrophysiology, with index $k$ in Eqs. 4 and 5 running through all experiments). The clustering of preferred orientations and its significance was evaluated with reproducibility measure, as described above.

To assess orientation tuning characteristics (see Fig. 8), we used a Gaussian model to fit orientation curves. Although it is not most appropriate to fit a cyclic function with a Gaussian (Swindale, 1998), we used this function to allow for comparison with common literature. Before fitting, sample orientations were adjusted (by adding or subtracting $180^{\circ}$ ) to the end of centering data points around the preferred orientation (Eq. 4). The fitting was performed with the nlinfit function of Matlab (for detailed description, see Sharon and Grinvald, 2002). The tuning width was defined as halfwidth at half-height $\left[\mathrm{HWHH}=(2 \ln 2)^{1 / 2} \sigma\right]$.

\section{Results}

We have imaged visually evoked activity of neuronal populations residing in the pigeon visual Wulst with high-resolution VSD optical imaging (Fig. 1). These neuronal populations were responding to large oriented gratings $\sim 120^{\circ}$ (length) $\times 80^{\circ}$ (height) in size.

\section{Focal emergence of visual Wulst activity is followed by rapid, far-reaching spread}

Figure 2 presents the spatiotemporal response dynamics across the visual Wulst to a drifting vertical grating presented for 800 ms. Each recorded frame depicts a temporal average of four frames ( $40 \mathrm{~ms}$ of activity) with the outset showing the first $70 \mathrm{~ms}$ in its original temporal resolution. The purple contours outline regions of highly significant $(p<0.01)$ activation (for threshold determination, see Materials and Methods).

Significant population activity was detected as early as $20-30 \mathrm{~ms}$ after stimulus onset. This focal region stereotactically approximates the portion of the intercalated hyperpallium apicale (IHA) that extrudes the surface (outlined in green). The rapid spread of activity extended anisotropically across the Wulst surface, along the border between the hyperpallium apicale (HA) (red) and hyperpallium intercalatum (HI) (blue), and, to a lesser extent, medially toward HA (compare Fig. $1 D$ ). Peak activation levels were reached $120 \mathrm{~ms}$ after stimulus onset. The response was homogeneous with no visible evidence of periodically clustered domains of orientationselective processing.

The observed spread most likely reflected arborizations connecting the input pseudolamina (IHA) to HA (Shimizu et al., 1995). The maximal speed of spread measured along posterior-anterior axis was $\sim 0.1 \mathrm{~m} / \mathrm{s}(N=9)$ at threshold level $(p<0.01)$ (Fig. 3). Although the presented gratings did not cover the entire yellow field (Fig. $1 C$ ), which spans $\sim 169^{\circ}$ (Martin and Young, 1983), it is unlikely that a larger visual stimulus would have produced a response that will emerge much less locally. Local grating patches $\left(20 \times 20^{\circ}\right)$ presented to different visual field regions evoked local emergence of activity with small offsets across this particular region. As with larger grating stimuli, initial activity was also followed by farreaching spread, and the summed response across all presented local stimuli also yielded a spatially similar onset region (supplemental Fig. 3, available at www.jneurosci.org as supplemental material). Additional support comes from previous studies in which receptive fields were hand-mapped (Gusel'nikov et al., 1977; Miceli et al., 1979; Deng and Wang, 1992): All authors found that most of their visually responsive neurons, and indeed the strongest firing, were found within a local 
A

VSD Imaging
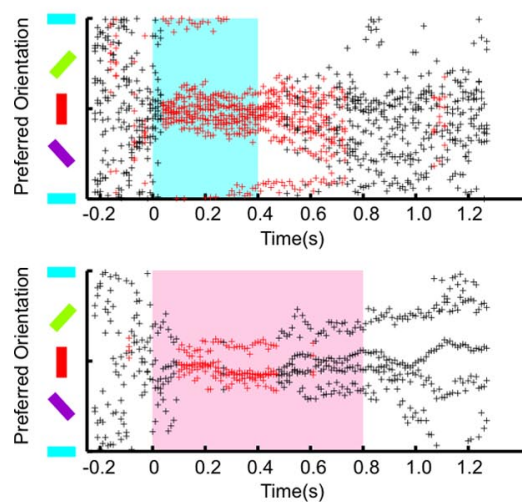

B

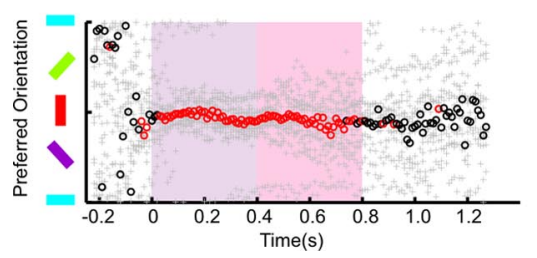

C
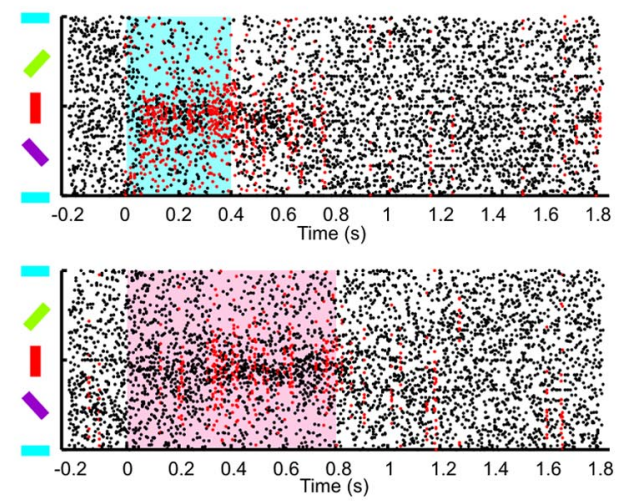

D

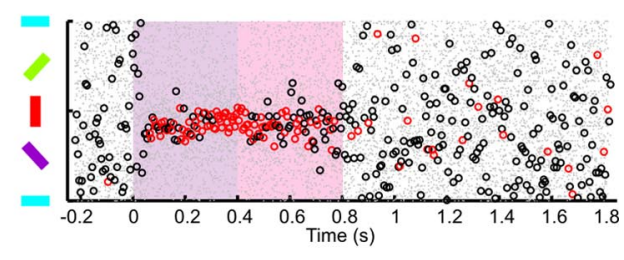

Figure 7. Preference for vertical orientation. $\boldsymbol{A}, \mathrm{VSD}$ imaging: The time course of orientation preference is shown separately for $400 \mathrm{~ms}$ (blue) and $800 \mathrm{~ms}$ (red) stimulus duration paradigms. The preferred orientation of pixels belonging to the input region of each animal is plotted with black dots; red color indicates significant clustering of orientation preference across animals in a given (10 ms) time frame, $p<0.05$ ( $N=9$ for $400 \mathrm{~ms} ; N=4$ for $800 \mathrm{~ms}$ ). $\boldsymbol{B}$, Summary across all experiments. The circles indicate the (vector) average of the orientations recorded in both paradigms (the light gray points show single experiments). There is a clear preference for vertical orientations across animals for at least the first $400 \mathrm{~ms}$ after stimulus onset $(p<0.05 ; N=9+4$ subjects). $\boldsymbol{C}$, Electrophysiology: The time course of orientation preference is shown similar to $\boldsymbol{A}$. The black dots represent preferred orientation recorded in 5 ms frames, averaged (by means of the vector average) across all cells recorded in a given animal and stimulus duration. When the stimulus is off, spikes recorded in a single millisecond are very sparse, yielding discrete clusters around orientations of the gratings (horizontal lines). This pattern changes, when the stimulus is on - a broad cluster of preferred orientations is visible around the vertical orientation. Their (vector) average is shown in $\boldsymbol{D}$ with red and black circles. $\boldsymbol{D}$, This summary plot was created from $5 \mathrm{~ms}$ binned data to increase the signal-to-noise ratio and the clarity of the image $(N=11+10)$ (for general description, see $\boldsymbol{B}$ ).

forebrain coordinate A12.0-A13.5; L1.5-L2.0, corresponding well to the focal response onset region imaged in the current study.

\section{Rapid adaptation in the visual Wulst}

We have seen that activity declined rapidly and peripheral parts of the visual Wulst returned to baseline before the stimulus was turned off, suggesting the presence of suppressive influences after the brief peak of the response.

To test whether this rapid adaptive effect was independent of input duration, stimulation was varied between $400 \mathrm{~ms}$ ("short") and $800 \mathrm{~ms}$ ("long") durations in an additional series of experiments. We first analyzed the central input region characterized by earliest response onsets (Fig. $4 A$, white pixels in inset; supplemental Fig. 1, available at www.jneurosci.org as supplemental material). For both the long (red) and the short stimulus condition (blue), time courses were obtained by averaging activity across all pixels belonging to this region.

We found that the brief peak response was followed by a similar immediate decline of activity in both conditions, indicating a fast-acting adaptive mechanism independent of stimulus durations. However, after the first rapid decay, a second drop in activity was followed coinciding with stimulus offsets. This indicated that responses in the central part of the Wulst were locked to stimulus duration at low amplitudes of activity (see black bar between 550 and $880 \mathrm{~ms} ; p<0.05$, unpaired $t$ test). The same was true of examined collective time courses of all cells $(N=127)$ measured by extracellular recordings (Fig. $4 B$ ). The close correspondence was expected since most units were recorded from the same area.

We then extended the analysis to the entire Wulst including also surrounding regions. For each pixel, we computed its offset latency defined as the time required for the signal to return to baseline levels. This calculation was done for long and short stimulus durations and an offset difference map was created (Fig. 4C). Together, it was confirmed that the central region was sensitive to stimulus duration (i.e., directly coupled to the stimulus), whereas the periphery showed a much stronger adaptation effect.

In sum, the observed spatiotemporal dynamics suggest that visual Wulst activity is locally initiated and coactivates strong suppressive mechanisms. Whereas activity within the central region is likely dominated by thalamic drive that may be sufficiently effective to override the buildup of suppression, surrounding regions receive input indirectly from remote locations and may be more sensitive to suppressive influences.

The striking similarity between the VSD signal and the spiking responses obtained with electrode recordings suggest a true neuronal origin of the VSD signal (Fig. 4, compare $A, B$ ). In separate experiments using $605 \mathrm{~nm}$ illumination, we additionally investigated whether the VSD signal may partially contain a "shine-through" of intrinsic hemodynamic signals, because of the prolonged "initial dip" that reflects local $\mathrm{O}_{2}$ consumption within active regions (supplemental Fig. 2, available at www.jneurosci.org as supplemental material). However, the onset of the intrinsic signals occurred at $\sim 350 \mathrm{~ms}$, thus much slower than the onset of the adaptation observed with VSD imaging $(\sim 120 \mathrm{~ms})$, further confirming that the observed rapid adaptation directly originated from neuronal activity.

\section{Dominant vertical orientation processing without orientation maps}

To evaluate the possible existence of orientation maps, we computed a polar map of the responses to differently oriented gratings (Fig. 5). Each pixel is color coded according to its preferred orientation, and its brightness is a confidence measure of how reproducible the preferred orientation is across trials (GrabskaBarwinska et al., 2009) (for determination of preferred orientation and reproducibility, see Materials and Methods). The two polar time courses computed for different stimulation durations in a representative subject revealed that most pixels were selective for vertical orientations (reddish colors).

It is unlikely that orientation maps were nonetheless present but were overwhelmed by the extensive spread of the dominant response evoked by vertical gratings. In fact, no orientation maps were found in differential maps, computed by subtracting the earliest responses to various orientations with orthogonal re- 
sponses (Fig. 6, left). Should orientation columns exist, the size of each orientation pinwheel must be extremely narrow $(<71$ $\mu \mathrm{m}$ or 1 pixel across), much smaller than what was recorded for the owl (Liu and Pettigrew, 2003), cat $(\sim 2 \mathrm{~mm})$ (Bonhoeffer and Grinvald, 1991), or ferret $(\sim 600-$ $700 \mu \mathrm{m}$ ) (Rockland, 1985). The same observation was true in the data derived by optical imaging of intrinsic signals. Figure 6 , right, shows the difference between time-averaged maps derived through optical imaging of intrinsic signals, averaged over $8 \mathrm{~s}$ of recording (for single frame, 400 ms resolution, see supplemental Fig. 2, available at www.jneurosci.org as supplemental material).

Although unlikely, we cannot totally exclude that orientation maps are present in those regions of the visual Wulst that are not parallel to the imaging plane, since maximal resolution of columnar structures is achieved only when columns are orthogonal to the imaging plane (as may be the case in the owl visual Wulst, which is hypertrophied compared with pigeon, rendering its pseudolaminas more evenly parallel to the surface (Pettigrew, 1979). However, because the tilting of the pseudolaminas in question (HA, IHA, and HI) did not comprise the entire imaged Wulst region (for threedimensional animation, see supplemental Movie 1, available at www.jneurosci.org as supplemental material), we would have expected to see at least partial signatures of columnar organization. Dense penetrations, and lowering of electrodes into the brain in small depth increments, particularly in the tilted regions, did not give any hint of periodic shifts in orientation selectivity. Finally, the dominant preference for vertical orientations across all imaged Wulst regions also argues against the presence of orientation maps.

Figure $7 A$ illustrates the evolution of orientation selectivity across time for each animal at $10 \mathrm{~ms}$ image resolution. Each data point plots the overall orientation preference of a single subject at a particular point in time. Data points were colored red if they were significantly clustered across animals (see Materials and Methods). As expected, during prestimulus and poststimulus times when a uniform gray screen was present, the distribution of orientation preference was not statistically different from a random distribution (i.e., $p>0.05$ ). However, for most animals, data points converged onto the $90^{\circ}$ orientation once the stimulus was applied. As the tuning curves were generally broad (see last paragraph in this section), the effect was subtle, specifically as our calculations were performed within short time intervals, which are particularly sensitive to noise. Therefore, the effect became more robust when pooling over a larger data set including also the measurements to the long stimulation protocol (Fig. $7 B$, open circles denote the average orientation preference across all animals and experiments).

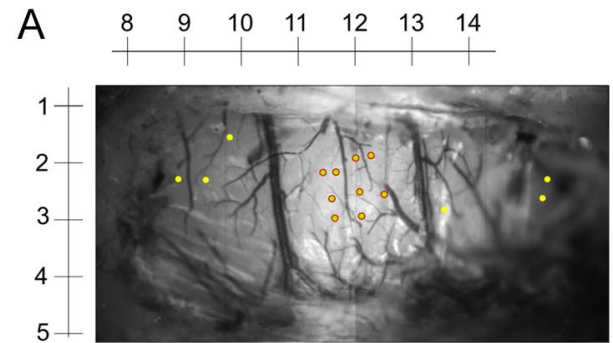

B Electrophysiology
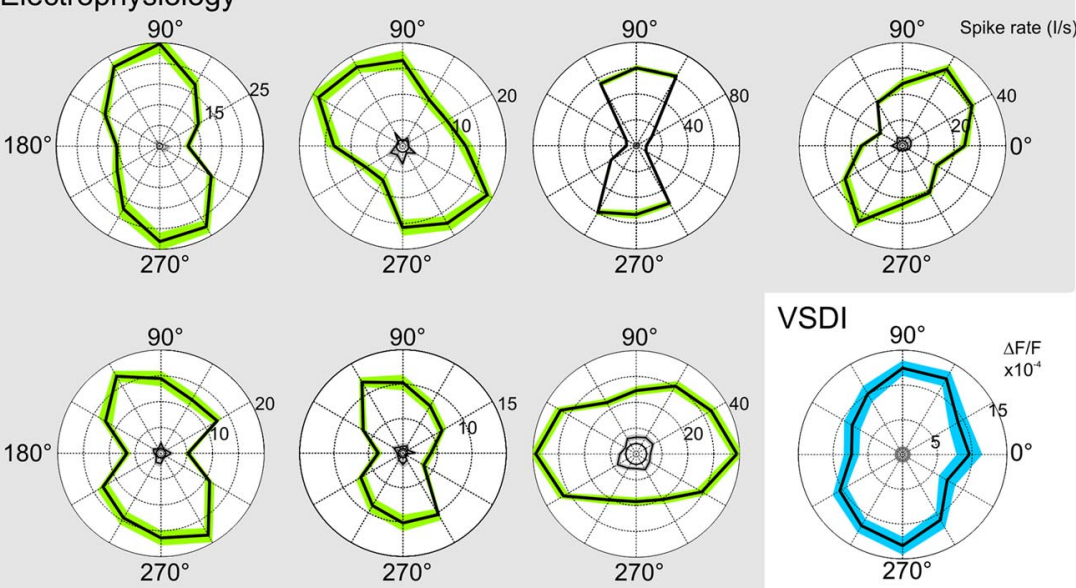

VSDI
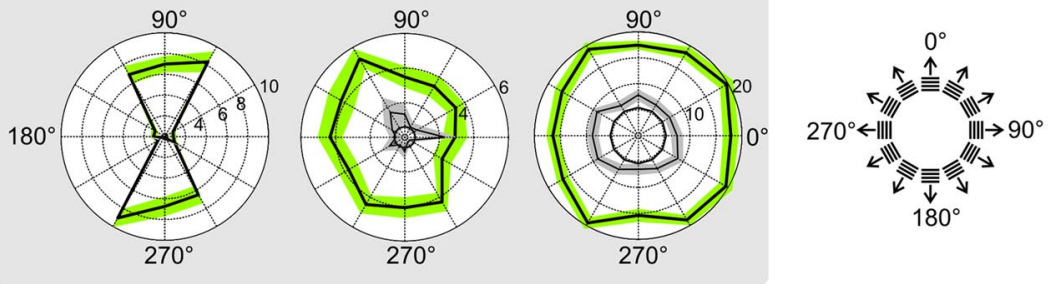

Figure 8. Single-cell and population orientation tuning. $A$, Majority of spiking units were found within a small locality of the visual Wulst. An example of penetration sites is shown here for one subject. The yellow markers are penetration sites where cells sulche

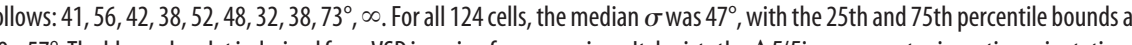
The dye signal was averaged over the " "input region" (Fig. 2; supplemental Figs. 1,3 , alin response to six grating orientations. mental material), across $20-420 \mathrm{~ms}$ after stimulus onset. The gray circle inside this plot represents mean activity ( $\pm \mathrm{SE})$ in response to the blank stimuli. A Gaussian fit of this plot gives a $\sigma$ of $45^{\circ}$. The median $\sigma$ across experiments was $62^{\circ}$, with the 25 th and 75 th percentile bounds at $48-91^{\circ}$.

The same analysis was applied to electrophysiological recordings at $5 \mathrm{~ms}$ resolution (Fig. $7 C$ ). In this case, the preferred orientations of all cells recorded in each animal were averaged by means of vector averaging (see Materials and Methods). Each data point represents the preferred orientation of all neurons of each animal at this time instance. Figure $7 D$ shows the summary after pooling long and short stimulus paradigms. As in Figure $7 B$, the open circles denote the average across all animals and experiments. In summary, both recording techniques complemented each other, showing the tendency that the bulk of visual Wulst neurons are preferably tuned to vertical orientation.

The majority of the responsive cells were located in a relatively confined region of the visual Wulst. In Figure 8A, a typical experiment is shown, in which the red dots mark penetration sites of responsive units, and the yellow dots represent penetration sites 


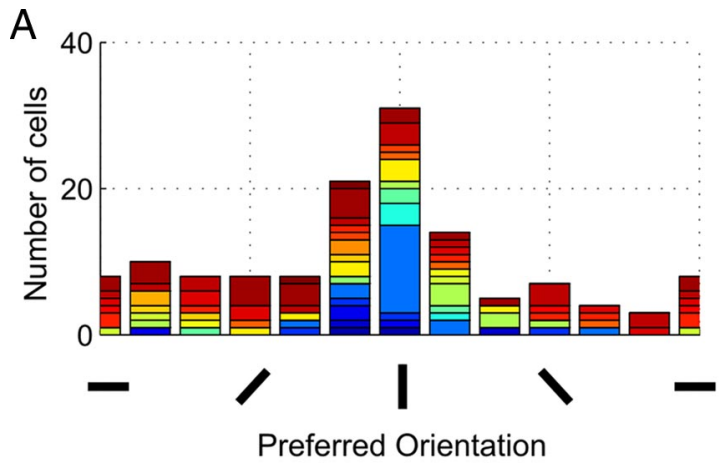

B

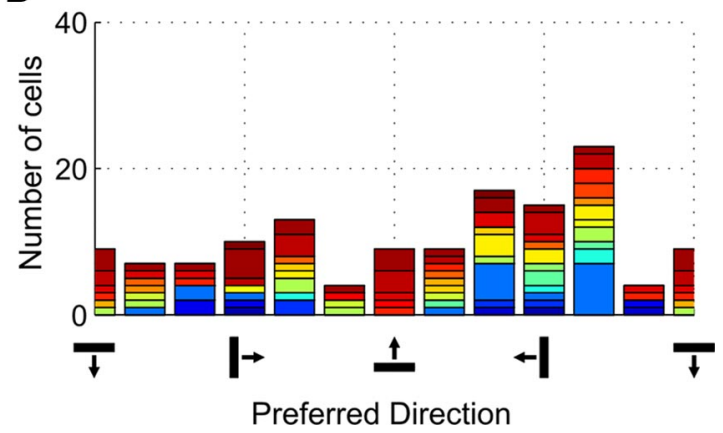

Figure 9. Vertical orientation anisotropy: temporal motion direction dominates. Histograms summarizing parametric preference of all available cells during $20-420 \mathrm{~ms}$ after stimulus onset. $\boldsymbol{A}$, Orientation selectivity. $\boldsymbol{B}$, Direction preference. For transparency, each color represents a different subject. Three cells were excluded from calculations in prestimulus time because prestimulus responses were extremely sparse and even across all orientations such that preferred orientation could not be calculated. The distribution of cells were tested with $\chi^{2}$ test. Prestimulus distributions did not significantly depart from a flat distribution, whereas cells were significantly clustered to vertical orientations after stimulus onset.

where no visually driven activity could be found. In consecutive electrode penetrations, we did not observe any sharp transitions in preferred orientation. The finding that visually responsive cells were located only in a limited region was interesting because evoked VSD signals spread quickly and extensively across the Wulst surface. This can be attributable to various reasons given that the VSD signal summates across a large volume of tissue. One possibility is that the majority of the neurons in the surrounding regions were activated but remained below firing threshold, or that the collected signal reflected spiking activity of a subpopulation of neurons that were sparsely distributed.

Figure $8 B$ is a representative collection of polar plots; each green polar plot represents the average firing rate of single cells between 20 and $420 \mathrm{~ms}$ after stimulus onset to each of 12 different gratings. Some units showed reduced activation to horizontal orientations (bow tie-shaped polar plots). Most other units respond selectively to different orientations with a range of medium to broad tuning widths. The blue polar plot is based on the responses of the VSD signal within the same time frame for comparison with population activity. Both neurons as well as dye responses show similar tuning to orientation. The median tuning width across all neurons was $56^{\circ}$, with 25 th and 75 th percentile bound at 46 and $67^{\circ}$, respectively; for the dye signal, HWHH was $73^{\circ}\left(57-108^{\circ}\right)$ (for details, see Materials and Methods and Fig. 8 legend). In comparison, $\mathrm{HWHH}$ imaged in cat area 18 is $\sim 35^{\circ}$ (Sharon and Grinvald, 2002).

Figure $9 A$ shows the distribution of orientation selectivity in the recorded population of cells from 12 animals. Each color represents a different animal from which cells were derived. The bias toward vertical orientations was highly significant $\left[\chi^{2}=\right.$ $\left.67(v=11 ; N=124), p=4.6 e^{-10}\right]$. This claim remains valid even after removing the large block population of $90^{\circ}$-selective cells that was recorded from a single animal (blue).

Forward motion dominates the natural locomotive behavior of most organisms, especially in flying birds. Considering that experiences in daily life can be reflected in neural activity, we further examined the data for direction selectivity (Fig. 9B). Here, we found that, on average, the population was biased toward forward (i.e., temporal motion) [preferring gratings drifting from right to left during left-eye stimulation, $\chi^{2}=32(v=11$; $\left.N=127), p=7.1 \times 10^{-4}\right]$. However, this direction bias was much weaker than the observed effect for vertical versus horizontal orientations. These findings suggest that the overrepresentation of vertical orientations is indeed experience related.

\section{Discussion}

We have distinguished two regions within the superficial pigeon Wulst based on their spatiotemporal characteristics, a central input area (IHA) and its surrounding region (HA, HI). Evoked activity rapidly adapted to ongoing visual stimulation, affecting both regions. Most orientation-selective cells were broadly tuned and were mainly selective for vertical orientations, with no indication of any periodic clustering of orientation-selective V1 cells commonly observed in many mammalian brains.

\section{Lack of orientation maps despite orientation selectivity}

The functions and origins underlying the orderly clustering of like-preferring orientation-selective V1 neurons is again under intense debate after the discovery that these cells are not clustered in the squirrel V1 (Van Hooser et al., 2005). Furthering the discussion, orientation pinwheels analogous to those found in cat and monkey V1 have been found in the barn owl visual Wulst (Liu and Pettigrew, 2003). This implied that the creation of orientation maps is shaped by convergent functional demands, given that the anatomical organization of $\mathrm{V} 1$ and the visual Wulst are fundamentally different.

The pseudolaminas of the Wulst are "flipped"; efferent projections to midbrain structures (e.g., optic tectum) (Reiner and Karten, 1983) are mediated by the superficial pseudolamina, HA. To our knowledge, there have been no reports of any horizontal intra-Wulst connections, similar to those in V1 commonly included in theoretical models of orientation map formation (Shouval et al., 2000; Ernst et al., 2001; Wolf, 2005; GrabskaBarwinska and von der Malsburg, 2008). The finding that orientation maps are nonetheless present in the owl Wulst contrasts our observation that those maps are absent in the pigeon, drawing parallels from the observations that mammalian carnivores have orientation maps but rodents do not.

The pigeon is a highly visual bird with particular strengths in luminance (Hodos et al., 1985) and color (Emmerton and Delius, 1980) discrimination, outperforming humans in these tasks. Its behavioral acuity $\left(12.6 \mathrm{cyc} /{ }^{\circ}\right)$ (Hahmann and Güntürkün, 1993) surpasses many mammalian species (Van Hooser and Nelson, 2006) and is even three times higher than the barn owl (Harmening et al., 2009). Against the owl, the pigeon Wulst may be less well differentiated in cytoarchitecture (Karten et al., 1973), receives less afferent input from the GLd, and has neurons with larger receptive fields $\left[4.5^{\circ}\right.$ (Miceli et al., 1979) vs $1-2^{\circ}$ in owls (Pettigrew, 1979)]. However, although lesser visual system differentiation could be one of the factors explaining the lack of maps in the pigeon, studies in mammals argue against a clear role of advanced 
Table 1. Binocular overlap and functional organization of orientation processing in the major animal models of vision

\begin{tabular}{|c|c|c|c|c|c|c|}
\hline Common name & Species & Order & Eye position & Orientation map ${ }^{a}$ & Binocular overlap ${ }^{b}$ & Orbital convergence $^{b}$ \\
\hline \multicolumn{7}{|l|}{ Mammals } \\
\hline Human & Homo sapiens & Primate & Frontal & $\sqrt{ }$ & $140^{\circ}$ & $79.3^{\circ}$ \\
\hline Macaque & Macaca mulatta & Primate & Frontal & $\sqrt{ }$ & $140^{\circ}$ & $73.9^{\circ}$ \\
\hline Owl monkey & Aotus trivirgatus & Primate & Frontal & $\sqrt{ }$ & $138^{\circ}$ & $67.5^{\circ}$ \\
\hline Marmoset & Callithrix jacchus & Primate & Frontal & $\sqrt{ }$ & $90-100^{\circ}$ & $55^{\circ}$ \\
\hline Cat & Felis silvestris & Carniovora & Frontal & $\sqrt{ }$ & $98-120^{\circ}$ & $66.3^{\circ}$ \\
\hline Ferret & Mustela putorius & Carniovora & Lateral & $\sqrt{ }$ & $80^{\circ}$ & $35.3^{\circ}$ \\
\hline Tree shrew & Tupaia glis & Scandentia & Lateral & $\sqrt{ }$ & $60^{\circ}$ & $32^{\circ}$ \\
\hline Squirrel & Sciurus carolinensis & Rodentia & Lateral & $x$ & $60^{\circ}$ & $22.1^{\circ}$ \\
\hline Rat & Rattus rattus & Rodentia & Lateral & $x$ & $40-60^{\circ}$ & $32^{\circ}$ \\
\hline Mouse & Mus musculus & Rodentia & Lateral & $x$ & $35-40^{\circ}$ & $38.3^{\circ}$ \\
\hline Rabbit & Lepus sp. & Lagomorpha & Lateral & $x$ & $24-32^{\circ}$ & $20^{\circ}$ \\
\hline \multicolumn{7}{|l|}{ Birds } \\
\hline Barn owl & Tyto alba & Strigiformes & Frontal & $\sqrt{ }$ & $44^{\circ}$ & $81.44^{\circ}$ \\
\hline Pigeon & Columba livia & Columbiformes & Lateral & $x$ & $22^{\circ}$ & $80.44^{\circ}$ \\
\hline
\end{tabular}

A general relationship exists between the presence of orientation maps and the extent to which an animal's eyes are frontally placed. Disregarding absolute numbers, animals that do not possess orientation maps in primary visual areas have approximately one-half the binocular overlap of animals that do. In birds, the maximal overlap is $40-50^{\circ}$ (kestrels) versus $140-150^{\circ}$ (primates) in mammals.

${ }^{a}$ Orientation maps: human (Yacoub et al., 2008); macaque (Blasdel and Salama, 1986); owl monkey (Xu et al., 2004); marmoset (McLoughlin and Schiessl, 2006); cat (Bonhoeffer and Grinvald, 1991); ferret (Weliky and Katz, 1994); tree shrew (Bosking et al., 1997); squirrel (Van Hooser et al., 2005); rat (Ohki et al., 2005); mouse, electrophysiology (Dräger, 1975); rabbit, electrophysiology (Bousfield, 1977; Murphy and Berman, 1979); barn owl (Liu and Pettigrew, 2003).

${ }^{b}$ Binocular overlap and orbit convergence. The references for these values were mainly derived from the study by Heesy (2004), his Table 1. Human (Vakkur and Bishop, 1963); macaque (Vakkur and Bishop, 1963; Ross, 1995); owl monkey (Allman and McGuinness, 1988); marmoset (Cartmill, 1971; Fritsches and Rosa, 1996); cat (Hughes, 1976; Arrese et al., 1999; Finarelli and Goswami, 2009); ferret (Garipis and Hoffmann, 2003); tree shrew (Hughes, 1977); squirrel (Kaas et al., 1972; Van Hooser et al., 2005); rat (Arrese et al., 1999); mouse (Dräger, 1978; Arrese et al., 1999); rabbit (Wall, 1942; Hughes and Vaney, 1982); barn owl (Iwaniuk et al., 2008); pigeon (Iwaniuk et al., 2008).

visual system development in the establishment of orientation maps (Van Hooser et al., 2005).

Instead, possibly a more important factor for the observed differences in the functional organization of orientation processing is eye position. This attribute alters the qualitative nature of input into the early visual forebrain. The pigeon visual Wulst receives mainly monocular information as a result of its laterally placed eyes and reduced representation of the frontal binocular field within its thalamofugal system (Remy and Güntürkün, 1991; Güntürkün and Hahmann, 1999) and its receptive fields seldom lay within the binocular visual field (Miceli et al., 1979). The owl's frontally placed eyes provide greater binocular overlap $\left(\sim 44^{\circ}\right)$ (Martin, 1984) and thus owls possess a larger proportion of visual Wulst neurons with binocular receptive fields (Pettigrew, 1979).

In mammals, there is no indication that large binocular overlap, and thus stereoscopic vision, can singly define the creation of orientation maps in the mammalian V1 (Van Hooser, 2007), although a general trend exists in which species with laterally placed eyes are lacking orientation maps (Table 1).

It is clear that the origins of extensive orientation-selective clustering will likely be multifaceted, possibly relating to the corepresentation of other visual features, number of extrastriate areas, evolutionary history, as well as the organism's behavior (below, we discuss consequences of lateral input). At this time, identifying those parameters would best benefit from the use of a larger, and more diverse, repertoire of animal models with distinct physical or behavioral traits. Here, we introduce a highly visual animal model of the avian class whose orientation-selective cells in its primary visual forebrain are not periodically clustered and suggest that binocular input may play a formative role in orientation mapping (Wiemer et al., 2000).

\section{The "horizontal effect": vertical anisotropy}

Orientation anisotropy in primary visual areas is a robust phenomenon ["oblique effect" (Appelle, 1972; Chapman and Bonhoeffer, 1998; Coppola et al., 1998a); "horizontal overrepresentation" (Girman et al., 1999; Li et al., 2003)] that is assumed to reflect natural environmental statistics dominated by vertical and hori- zontal ("cardinal") orientations compared with oblique ones (Coppola et al., 1998b). Such anisotropies have not been systematically studied in the pigeon; however, one may still assume that the overrepresentation of vertical contours here could be related to environmental input and behavior. In fact, the observed response bias for gratings moving in temporal direction supports such an assumption. The visual receptive field of the Wulst is mainly lateral with the area centralis projecting $\sim 60^{\circ}$ away from the beak at rest (Nalbach et al., 1990). Together with the pigeon's high flight speed low over ground and its walking pattern characterized by head bobbing (Friedman, 1975), the pigeon's visual Wulst is therefore either "constantly" or "repetitively" exposed to a rapid and horizontally drifting optic flow field.

According to the energy model of feature representation in V1 (Adelson and Bergen, 1985; Basole et al., 2003; Baker and Issa, 2005), fast moving stimuli generate motion streak phenomena (Burr, 1980; Geisler, 1999). This is reflected when visual cortical neurons respond to the orientation of the motion axis rather than to the individual orientation of rapidly moving objects (Jancke, 2000; Geisler et al., 2001). Thus, in the case of the pigeon Wulst, it may be functionally beneficial to reduce this excessive and redundant representation of horizontal motion streaks. In fact, we found that not only fewer neurons preferred horizontal orientations but some were also selectively unresponsive to horizontal gratings. This hypothesis does not contradict the idea of exposure-related overrepresentation proposed to underlie the oblique effect by assuming that it subserves transmission of meaningful orientation information, rather than a general bias of environmental statistics (for analogous findings, see Schnabel et al., 2006; Schnabel, 2008). In human psychophysics, even a short preexposure to horizontal gratings led to adaptation effects that indirectly increased sensitivity to vertical orientations (Clifford et al., 2001).

One may only speculate about the manner in which the horizontal effect is brought about. One possibility is given by the consideration that horizontal motion produces also motion energy that strongly activates neurons preferring vertical orientations (Jancke, 2000; Mante and Carandini, 2005) (for recent review, see Issa et al., 2008). This effect, although ubiquitous, is 
more prominent at lower speeds because of the specific spatiotemporal bandwidth of visual neurons. According to this hypothesis, the observed anisotropy would then directly mirror the persistent vertical input. In turn, the increased numbers of vertically selective neurons could provide the neural pool for suppressive normalization of the dominant horizontal motion energy.

Along this line, Essock et al. (2009) proposed a suppressive normalization mechanism helping to discount the overrepresentation of orientation content (horizontal) in the environment, after the finding that horizontal orientations were most strongly suppressed (vs vertical and oblique ones) by prestimulus exposure to oriented broadband masks. Broadband stimuli are more naturalistic, and, under such conditions, humans showed least sensitivity toward horizontal orientations (horizontal effect) (Essock et al., 2003). The normalization may then serve to increase salience of statistically less prevalent content (vertical orientations) under natural viewing conditions (Hansen and Essock, 2004). As for the pigeon, the bias in input statistic is not a property of the environment per se but rather self-generated through the pigeon's locomotive behavior; the observed vertical anisotropy may therefore be the result of a compensatory process that facilitates the acquisition of vertical landmarks.

\section{Rapid adaptation: possible top-down tectal switch?}

The sideway motion inherent to the pigeon's visual input may also explain the rapid adaptation of the visual Wulst. The pigeon exhibits a peculiar head-bobbing behavior, which is a repetitive head motion pattern consisting of two alternating phases. In the hold phase lasting $\sim 120 \mathrm{~ms}$, the head is kept stable in space (Troje and Frost, 2000). A thrust phase then follows to allow the head to catch up with the moving body (Friedman, 1975). Visual discrimination is possible using the lateral visual field during both these phases, even in the thrust phase in which optic flow is much larger (Jiménez Ortega et al., 2009). Such behavior thus forces the visual system to deal with two radically different, and rapidly alternating, input conditions.

Rapid intraareal adaptation across large ensembles of neurons has recently been visualized in monkey V1 using VSD imaging (Sit et al., 2009). Such gain-control mechanisms are likely to affect brain areas further downstream. The HA of the Wulst sends an especially strong descending input on the optic tectum (Manns et al., 2007) with which it can regulate the tectofugal system (Hellmann and Güntürkün, 2001), the most prominent visual pathway in pigeons. When stimulated before the optic nerve, the Wulst can "sharpen" responses by dampening spontaneous activity in the optic tectum, possibly through the coactivation of local inhibitory circuits (Bagnoli et al., 1977). Here, it was shown that the HA can indeed operate at rapid timescales since suppressive mechanisms that curb evoked activity became evident as early as $130 \mathrm{~ms}$ after stimulus onset. Its rapid adaptation supports the view that the HA may act as a "top-down" tectal switch to alter the computational mode of tectal neurons in tandem with alternating changes in visual input.

\section{Future directions}

Here, we have for the first time explored population activity of the pigeon homolog to the primary visual cortex using simple grating stimuli conventionally used to evaluate the most prominent V1 function of orientation selectivity. In future studies, it will be interesting to test these findings and verify our hypotheses in awake behaving animals using static versus flow field stimulation.

\section{References}

Adelson EH, Bergen JR (1985) Spatiotemporal energy models for the perception of motion. J Opt Soc Am A 2:284-299.

Allman J, McGuinness E (1988) Visual cortex in primates. In: Comparative primate biology, Vol 4, Neurosciences (Steklis HD, Erwin, J, eds), pp 279-326. New York: Alan R. Liss.

Appelle S (1972) Perception and discrimination as a function of stimulus orientation: the "oblique effect" in man and animals. Psychol Bull 78:266-278.

Arrese C, Dunlop SA, Harman AM, Braekevelt CR, Ross WM, Shand J, Beazley LD (1999) Retinal structure and visual acuity in a polyprotodont marsupial, the fat-tailed dunnart (Sminthopsis crassicaudata). Brain Behav Evol 53:111-126.

Aust U, Huber L (2006) Picture-object recognition in pigeons: evidence of representational insight in a visual categorization task using a complementary information procedure. J Exp Psychol Anim Behav Process 32:190-195.

Bagnoli B, Francesconi W, Magni F (1977) Visual Wulst influences on the optic tectum of the pigeon. Brain Behav Evol 14:217-237.

Baker TI, Issa NP (2005) Cortical maps of separable tuning properties predict population responses to complex visual stimuli. J Neurophysiol 94:775-787.

Basole A, White LE, Fitzpatrick D (2003) Mapping multiple features in the population response of visual cortex. Nature 423:986-990.

Blasdel GG, Salama G (1986) Voltage-sensitive dyes reveal a modular organization in monkey striate cortex. Nature 321:579-585.

Bonhoeffer T, Grinvald A (1991) Iso-orientation domains in cat visual cortex are arranged in pinwheel-like patterns. Nature 353:429-431.

Bosking WH, Zhang Y, Schofield B, Fitzpatrick D (1997) Orientation selectivity and the arrangement of horizontal connections in tree shrew striate cortex. J Neurosci 17:2112-2127.

Bousfield JD (1977) Columnar organisation and the visual cortex of the rabbit. Brain Res 136:154-158.

Brooks DI, Wasserman EA (2008) Same/different discrimination learning with trial-unique stimuli. Psychon Bull Rev 15:644-650.

Burr D (1980) Motion smear. Nature 284:164-165.

Cartmill M (1971) Ethmoid component in the orbit of primates. Nature 232:566-567.

Chapman B, Bonhoeffer T (1998) Overrepresentation of horizontal and vertical orientation preferences in developing ferret area 17. Proc Natl Acad Sci U S A 95:2609-2614.

Clifford CW, Wyatt AM, Arnold DH, Smith ST, Wenderoth P (2001) Orthogonal adaptation improves orientation discrimination. Vision Res 41:151-159.

Cook RG, Smith JD (2006) Stages of abstraction and exemplar memorization in pigeon category learning. Psychol Sci 17:1059-1067.

Cook RG, Katz JS, Cavoto BR (1997) Pigeon same-different concept learning with multiple stimulus classes. J Exp Psychol Anim Behav Process 23:417-433.

Coppola DM, White LE, Fitzpatrick D, Purves D (1998a) Unequal representation of cardinal and oblique contours in ferret visual cortex. Proc Natl Acad Sci U S A 95:2621-2623.

Coppola DM, Purves HR, McCoy AN, Purves D (1998b) The distribution of oriented contours in the real world. Proc Natl Acad Sci USA 95:4002-4006.

Deng C, Wang B (1992) Overlap of somatic and visual response areas in the Wulst of pigeon. Brain Res 582:320-322.

Dräger UC (1975) Receptive fields of single cells and topography in mouse visual cortex. J Comp Neurol 160:269-290.

Dräger UC (1978) Observations on monocular deprivation in mice. J Neurophysiol 41:28-42.

Emmerton J, Delius JD (1980) Wavelength discrimination in the "visible" and ultraviolet spectrum by pigeons. J Comp Physiol 141:47-52.

Erichsen JT, Hodos W, Evinger C, Bessette BB, Phillips SJ (1989) Head orientation in pigeons: postural, locomotor and visual determinants. Brain Behav Evol 33:268-278.

Ernst U, Pawelzik K, Sahar-Pikielny C, Tsodyks M (2001) Intracortical origin of visual maps. Nature 4:431-436.

Essock EA, DeFord JK, Hansen BC, Sinai MJ (2003) Oblique stimuli are seen best (not worst!) in naturalistic broad-band stimuli: a horizontal effect. Vision Res 43:1329-1335.

Essock EA, Haun AM, Kim YJ (2009) An anisotropy of orientation-tuned 
suppression that matches the anisotropy of typical natural scenes. J Vis 9:1-15.

Finarelli JA, Goswami A (2009) The evolution of orbit orientation and encephalization in the Carnivora (Mammalia). J Anat 214:671-678.

Friedman MB (1975) Visual control of head movements during avian locomotion. Nature 255:67-69.

Fritsches KA, Rosa MG (1996) Visuotopic organisation of striate cortex in the marmoset monkey (Callithrix jacchus). J Comp Neurol 372:264-282.

Garipis N, Hoffmann KP (2003) Visual field defects in albino ferrets (Mustela putorius furo). Vision Res 43:793-800.

Geisler WS (1999) Motion streaks provide a spatial code for motion direction. Nature 400:65-69.

Geisler WS, Albrecht DG, Crane AM, Stern L (2001) Motion direction signals in the primary visual cortex of cat and monkey. Vis Neurosci 18:501-516.

Ghosh N, Lea SE, Noury M (2004) Transfer to intermediate forms following concept discrimination by pigeons: chimeras and morphs. J Exp Anal Behav 82:125-141.

Girman SV, Sauvé Y, Lund RD (1999) Receptive field properties of single neurons in rat primary visual cortex. J Neurophysiol 82:301-311.

Grabska-Barwinska A, von der Malsburg C (2008) Establishment of a scaffold for orientation maps in primary visual cortex of higher mammals. J Neurosci 28:249-257.

Grabska-Barwinska A, Distler C, Hoffmann KP, Jancke D (2009) Contrast independence of cardinal preference: stable oblique effect in orientation maps of ferret visual cortex. Eur J Neurosci 29:1258-1270.

Grinvald A, Lieke EE, Frostig RD, Hildesheim R (1994) Cortical pointspread function and long-range lateral interactions revealed by real-time optical imaging of macaque monkey primary visual cortex. J Neurosci 14:2545-2568.

Güntürkün O, Hahmann U (1999) Functional subdivisions of the ascending visual pathways in the pigeon. Behav Brain Res 98:193-201.

Gusel'nikov VI, Morenkov ED, Hunh DC (1977) Responses and properties of receptive fields of neurons in the visual projection zone of the pigeon hyperstriatum. Neurosci Behav Physiol 8:210-215.

Hahmann U, Güntürkün O (1993) The visual acuity for the lateral visual field of the pigeon (Columba livia). Vision Res 33:1659-1664.

Hansen BC, Essock EA (2004) A horizontal bias in human visual processing of orientation and its correspondence to the structural components of natural scenes. J Vis 4:1044-1060.

Harmening WM, Nikolay P, Orlowski J, Wagner H (2009) Spatial contrast sensitivity and grating acuity of barn owls. J Vis 9:13.

Heesy CP (2004) On the relationship between orbit orientation and binocular visual field overlap in mammals. Anat Rec A Discov Mol Cell Evol Biol 281:1104-1110.

Hellmann B, Güntürkün O (2001) Structural organization of parallel information processing within the tectofugal visual system of the pigeon. J Comp Neurol 429:94-112.

Hodos W, Bassette BB, Macko KA, Weiss SR (1985) Normative data for pigeon vision. Vision Res 25: 1525:1527.

Hughes A (1976) A supplement to the cat schematic eye. Vision Res 16:149-154.

Hughes A (1977) The topography of vision in mammals of contrasting lifestyle: comparative optics and retinal organization. In: The visual system in vertebrates (Crescitelli F, ed), pp 613-756. New York: Springer.

Hughes A, Vaney DI (1982) The organization of binocular cortex in the primary visual area of the rabbit. J Comp Neurol 204:151-164.

Issa NP, Rosenberg A, Husson TR (2008) Models and measurements of functional maps in V1. J Neurophysiol 99:2745-2754.

Iwaniuk AN, Heesy CP, Hall MI, Wylie DRW (2008) Relative Wulst volume is correlated with orbit orientation and binocular visual field in birds. J Comp Physiol A Neuroethol Sens Neural Behav Physiol 194:267-282.

Jancke D (2000) Orientation formed by a spot's trajectory: a twodimensional population approach in primary visual cortex. J Neurosci 20:RC86(1-6).

Jancke D, Chavane F, Naaman S, Grinvald A (2004) Imaging cortical correlates of illusion in early visual cortex. Nature 428:423-426.

Jarvis ED, Güntürkün O, Bruce L, Csillag A, Karten H, Kuenzel W, Medina L, Paxinos G, Perkel DJ, Shimizu T, Striedter G, Wild JM, Ball GF, DugasFord J, Durand SE, Hough GE, Husband S, Kubikova L, Lee DW, Mello CV, et al. (2005) Avian brains and a new understanding of vertebrate brain evolution. Nat Rev Neurosci 6:151-159.
Jiménez Ortega L, Stoppa K, Güntürkün O, Troje N (2009) Vision during head bobbing: are pigeons capable of shape discrimination during the thrust phase? Exp Brain Res 199:313-321.

Kaas JH, Hall WC, Diamond IT (1972) Visual cortex of the grey squirrel (Sciurus carolinensis): architectonic subdivisions and connections from the visual thalamus. J Comp Neurol 145:273-305.

Karten H, Hodos W (1967) A stereotaxic atlas of the brain of the pigeon (Columba livia). Baltimore: Johns Hopkins.

Karten HJ, Hodos W, Nauta WJ, Revzin AM (1973) Neural connections of the "visual Wulst" of the avian telencephalon. Experimental studies in the piegon (Columba livia) and owl (Speotyto cunicularia). J Comp Neurol 150:253-278.

Lazareva OF, Freiburger KL, Wasserman EA (2004) Pigeons concurrently categorize photographs at both basic and superordinate levels. Psychon Bull Rev 11:1111-1117.

Lazareva OF, Freiburger KL, Wasserman EA (2006) Effects of stimulus manipulations on visual categorization in pigeons. Behav Processes 72:224-233.

Li B, Peterson MR, Freeman RD (2003) Oblique effect: a neural basis in the visual cortex. J Neurophysiol 90:204-217.

Liu GB, Pettigrew JD (2003) Orientation mosaic in barn owl's visual Wulst revealed by optical imaging: comparison with cat and monkey striate and extra-striate areas. Brain Res 961:153-158.

Manns M, Freund N, Patzke N, Güntürkün O (2007) Organization of telencephalotectal projections in pigeons: impact for lateralized top-down control. Neuroscience 144:645-653.

Mante V, Carandini M (2005) Mapping of stimulus energy in primary visual cortex. J Neurophysiol 13:788-798.

Martin GR (1984) The visual fields of the tawny owl (Strix aluco). Vision Res 24:1739-1751.

Martin GR, Young SR (1983) The retinal binocular field of the pigeon (Columba livia): English racing homer. Vision Res 23:911-915.

McLoughlin N, Schiessl I (2006) Orientation selectivity in the common marmoset (Callithrix jacchus): the periodicity of orientation columns in V1 and V2. Neuroimage 31:76-85.

Medina L, Reiner A (2000) Do birds possess homologues of mammalian primary visual, somatosensory and motor cortices? Trends Neurosci 23:1-12.

Miceli D, Gioanni H, Repérant J, Perichoux J (1979) The avian visual Wulst: I. An anatomical study of afferent and efferent pathways. II. An electrophysiological study of the functional properties of single neurons. In: Neural mechanisms of behavior in birds (Granda AM, Maxwell JH, eds), pp 223-254. New York: Plenum.

Murphy EH, Berman N (1979) The rabbit and the cat: a comparison of some features of response properties of single cells in the primary visual cortex. J Comp Neurol 188:401-427.

Nagasaka Y, Wasserman EA (2008) Amodal completion of moving objects by pigeons. Perception 37:557-570.

Nalbach HO, Wolf-Oberhollenzer F, Kirschfeld K (1990) The pigeon's eye viewed through an ophthalmoscopic microscope: orientation of retinal landmarks and significance of eye movements. Vision Res 30:529-540.

Nieder A, Wagner H (1999) Perception and neuronal coding of subjective contours in the owl. Nat Neurosci 2:660-663.

Nieder A, Wagner H (2001) Hierarchical processing of horizontal disparity information in the visual forebrain of behaving owls. J Neurosci 21:4514-4522.

Ohki K, Chung S, Ch'ng YH, Kara P, Reid RC (2005) Functional imaging with cellular resolution reveals precise micro-architecture in visual cortex. Nature 433:597-603.

Palagina G, Eysel UT, Jancke D (2009) Strengthening of lateral activation in adult rat visual cortex after retinal lesions captured with voltage-sensitive dye imaging in vivo. Proc Natl Acad Sci U S A 106:8743-8747.

Petersen CC, Grinvald A, Sakmann B (2003) Spatiotemporal dynamics of sensory responses in layer $2 / 3$ of rat barrel cortex measured in vivo by voltage-sensitive dye imaging combined with whole-cell voltage recordings and neuron reconstructions. J Neurosci 23:1298-1309.

Pettigrew JD (1979) Binocular visual processing in the owl's telencephalon. Proc R Soc Lond B Biol Sci 204:435-454.

Pettigrew JD, Konishi M (1976) Neurons selective for orientation and binocular disparity in the visual Wulst of the barn owl (Tyto alba). Science 193:675-678.

Prechtl JC, Cohen LB, Pesaran B, Mitra PP, Kleinfeld D (1997) Visual stim- 
uli induce waves of electrical activity in turtle cortex. Proc Natl Acad Sci U S A 94:7621-7626.

Ratzlaff EH, Grinvald A (1991) A tandem-lens epifluorescence macroscope: hundred-fold brightness advantage for wide-field imaging. J Neurosci Methods 36:127-137.

Reiner A, Karten HJ (1983) The laminar source of efferent projections from the avian Wulst. Brain Res 275:349-354.

Reiner A, Perkel DJ, Bruce LL, Butler AB, Csillag A, Kuenzel W, Medina L, Paxinos G, Shimizu T, Striedter G, Wild M, Ball GF, Durand S, Güntürkün O, Lee DW, Mello CV, Powers A, White SA, Hough G, Kubikova $\mathrm{L}$, et al. (2004) Revised nomenclature for avian telencephalon and some related brainstem nuclei. J Comp Neurol 473:377-414.

Remy M, Güntürkün O (1991) Retinal afferents to the tectum opticum and the nucleus opticus principalis thalami in the pigeon. J Comp Neurol 305:57-70.

Rockland KS (1985) Anatomical organization of primary visual cortex (area 17) in the ferret. J Comp Neurol 241:225-236.

Ross CF (1995) Allometric and functional influences on primate orbit orientation and the origins of the Anthropoidea. J Hum Evol 29:201-227.

Schnabel M (2008) A symmetry of the visual world in the architecture of the visual cortex. $\mathrm{PhD}$ thesis, Goettingen University.

Schnabel M, Kaschube M, White LE, Coppola D, Löwel S, Wolf F (2006) Signatures of shift-twist symmetry in natural images and orientation maps. FENS Abstr 3:A179.30.

Seidemann E, Arieli A, Grinvald A, Slovin H (2002) Dynamics of depolarization and hyperpolarization in the frontal cortex and saccade goal. Science 295:862-865.

Senseman DM, Robbins KA (1999) Modal behavior of cortical neural networks during visual processing. J Neurosci 19:RC3(1-7).

Sharon D, Grinvald A (2002) Dynamics and constancy in cortical spatiotemporal patterns of orientation processing. Science 295:512-515.

Sharon D, Jancke D, Chavane F, Na'aman S, Grinvald A (2007) Cortical response field dynamics in cat visual cortex. Cereb Cortex 17:2866-2877.

Shimizu T, Cox K, Karten HJ (1995) Intratelencephalic projections of the visual Wulst in pigeons (Columba livia). J Comp Neurol 359:551-572.

Shouval HZ, Goldberg DH, Jones JP, Beckerman M, Cooper LN (2000) Structured long-range connections can provide a scaffold for orientation maps. J Neurosci 20:1119-1128.
Sit YF, Chen Y, Geisler WS, Miikkulainen R, Seidemann E (2009) Complex dynamics of $\mathrm{V} 1$ population responses explained by a simple gain-control model. Neuron 64:943-956.

Sterkin A, Lampl I, Ferster D, Grinvald A, Arieli A (1998) Real time optical imaging in cat visual cortex exhibits high similarity to intracellular activity. Neurosci Lett 51:S41.

Swindale NV (1998) Orientation tuning curves: empirical description and estimation of parameters. Biol Cybern 78:45-56.

Troje NF, Frost BJ (2000) Head-bobbing in pigeons: how stable is the hold phase? J Exp Biol 203:935-940.

Vakkur GJ, Bishop PO (1963) The schematic eye in the cat. Vision Res 61:357-381.

Van Hooser SD (2007) Similarity and diversity in visual cortex: is there a unifying theory of cortical computation? Neuroscientist 13:639-656.

Van Hooser SD, Nelson SB (2006) The squirrel as a rodent model of the human visual system. Vis Neurosci 23:765-778.

Van Hooser SD, Heimel JA, Chung S, Nelson SB, Toth LJ (2005) Orientation selectivity without orientation maps in visual cortex of a highly visual mammal. J Neurosci 25:19-28.

Wall GL (1942) The vertebrate eye and its adaptive radiation. New York: Hafner.

Weliky M, Katz LC (1994) Functional mapping of horizontal connections in developing ferret visual cortex: experiments and modeling. J Neurosci 14:7291-7305.

Wiemer J, Burwick T, von Seelen W (2000) Self-organizing maps for visual feature representation based on natural binocular stimuli. Biol Cybern 82:97-110.

Wolf F (2005) Symmetry, multistability, and long-range interactions in brain development. Phys Rev Lett 95:208701.

Xu X, Bosking W, Sáry G, Stefansic J, Shima D, Casagrande V (2004) Functional organization of visual cortex in the owl monkey. J Neurosci 24:6237-6247.

Yacoub E, Harel N, Ugurbil K (2008) High-field fMRI unveils orientation columns in humans. Proc Natl Acad Sci U S A 105:10607-10612.

Yamazaki Y, Aust U, Huber L, Hausmann M, Güntürkün O (2007) Lateralized cognition: asymmetrical and complementary strategies of pigeons during discrimination of the "human concept." Cognition 104:315344. 